\title{
Errors and Omissions in Private Clinics Prescriptions: A Survey of Prescription Writing In Duhok, Kurdistan Region- Iraq
}

Reveng Abdullah Abdulkareem, Omer Q. B. Allela*, Salman d. Haji, Zozan kh edoo, Nadia m. Rasheed and Karina k. Ali

School of Pharmacy, Faculty of Medical Science, University of Duhok (UOD), Duhok, 42001 Iraq

\begin{abstract}
Background and aim: Prescriptions errors are currently a worldwide public health issue and it is one of the most serious errors. The aim of this study was to screen drug prescriptions written by physicians in outpatient private
\end{abstract} clinics in Duhok city for the essential elements of prescriptions.

Method: Cross-sectional study was carried out in private five outpatient clinics. Convenient samples of 516 prescriptions were collected from the selected private clinics and reviewed for the presence and accuracy of information contained.

Results: Only $18.25 \%$ of the drug written in generic name and $40.74 \%$ as trade name. $87.46 \%$ of the prescribed drugs have the drug frequency on and $12.54 \%$ do not have the frequency on. The majority $(64.10 \%)$ of the drugs prescribed in Duhok city are found without any consideration to food intake $61.63 \%$ of the prescriptions have it is the physician registration number. $96.32 \%$ of the prescriptions collected include the name of the patient, $46.90 \%$ includes the age, and only $5.43 \%$ includes the sex.

Conclusion: Many errors found in prescriptions reviewed and most of the physicians don't follow the rules for standard prescribing pattern. Moreover, patients might be at risk of therapeutic failure due to errors happen during the prescription writing, dispensing and administration

Keywords: Prescriptions; Errors; Physician; Pharmacist; DuhokIraq

\section{Background and Objectives}

The concept of prescriptions dates back to the beginning of history. So long as there were medications and a writing system to capture directions for preparation and usage, there were prescriptions [1].

A drug prescription is often the final step of a patient's visit to a physician. As a direction from a prescriber to a dispenser, prescription is considered to be a medico legal document that should be written clearly, precisely and completely $[2,3]$.

There are two categories of prescription those written for a single component or prefabricated product and not requiring compounding or admixture by the pharmacist, and those written for more than a single component and requiring compounding [4].

Prescriptions errors are currently a worldwide public health issue and it is one of the most serious errors. A good quality prescriptions are extremely important for minimizing errors in the dispensing of medications, physicians should adhere to the guidelines for prescription writing for the benefit of the patient [4].

Inadvertent drug substitutions occurred in several instances in our practices due to the combination of the physician's illegible handwriting on prescriptions and the pharmacist's misinterpretation of subtle clues [5].

Recommendations to minimizing illegibility include using preprinted prescription pads, training staff assistants who write prescriptions, printing complete directions on each prescription, and aggressively educating each patient about the name and purpose of all drugs being prescribed [6].

The aim of this study was to screen drug prescriptions written by physicians in outpatient private clinics in Duhok city for the essential elements of prescriptions.

\section{Methodology}

Cross-sectional study was carried out in private five outpatient clinics (Duhok private hospital, Vajeen private hospital, Sheelan private hospital, Zeriland medical complex and clinics in the city center) in Duhok city, Iraq.

This study focused on the collection of prescription randomly from each area regarding to four specialty of physician, which are internal medicines, obstetrics and gynecology, surgery and pediatric. The samples had been taken according to simple random sampling method.

This study depends in most instances on private community pharmacies that are near to the clinics. Prescriptions were taken from private pharmacies during patients' attendance to the pharmacy. Data collection was conducted over a period of five months from October 1, 2013 through February 30, 2014.

Convenient samples of 516 prescriptions were collected from the selected private clinics and reviewed for the presence and accuracy of information contained. The data collection was taking a photo for each prescription under supervision of the pharmacist in each private pharmacy. The prescriptions were examined for the completeness of information.

*Corresponding author: Omer QB Allela, Clinical Pharmacy, School of Pharmacy, Faculty of Medical Science, University of Duhok (UOD), Duhok, 42001-Iraq, Itaq, Tel: 9640627222292; E-mail: omarallela@yahoo.com

Received: June 28, 2016; Accepted July 12, 2016; Published July 18, 2016

Citation: Abdulkareem RA, Omer QBA, Haji SD, Zozankh E, Rasheed NM, et al. (2016) Errors and Omissions in Private Clinics Prescriptions: A Survey of Prescription Writing In Duhok, Kurdistan Region- Iraq. J Pharmacovigilance 4: 215. doi:10.4172/2329-6887.1000215

Copyright: (c) 2016 Abdulkareem RA, et al. This is an open-access article distributed under the terms of the Creative Commons Attribution License, which permits unrestricted use, distribution, and reproduction in any medium, provided the original author and source are credited. 
Compliance with the elements of prescription writing was defined as the degree to which the physician had met the obligation of including all the elements of a prescription in the prescription order.

A permission to carry out the study was obtained from the pharmacist syndicate in Duhok. The study proposal was approved by College of pharmacy- University of Duhok (UOD). In order to keep the confidentiality of the collected data the physician and patients name had been excluded.

\section{Results and Discussion}

\section{Drugs' name}

Regarding the medicine's name prescribed by the physicians, they either write a generic name of the medicine or its trade name or the commercial name. Figure 1 showed the percentage of drugs written in generic, brand and commercial name in the prescriptions in Duhok city.

Only $18.25 \%$ of the drug written in generic name and $40.74 \%$ as trade name. Brand name drugs are typically more expensive than generic drugs, and prices for brand have historically increased more than those for generic-name drugs [3,7-10].

Unfortunately $38.69 \%$ of the drug prescribed using a commercial name which is non-official name and not presented in any drug guide or a generic name written but with a company name specified by the physician. Economic factors may play a role, as some pharmaceutical companies pay rewards to doctors who prescribe their products and this discourages generic prescribing [11,12].

The handwriting and wrong spell were two problems for pharmacist during dispensing the prescription and considered as a source of treatment failure [12]. $4.25 \%$ of the prescriptions are unreadable due to unclear handwritings of the doctors and $4.91 \%$ of the drug written in wrong spell.

\section{Drugs' frequency}

Out of 516 prescriptions, $87.46 \%$ of the prescribed drugs have the drug frequency on and $12.54 \%$ do not have the frequency on. Just as the dose and the dosage form of the drug, drug frequency is an essential thing that the doctors need to carefully take care of. It is stressed that all drugs should have frequency written on; even for over-the-counter since it is also drugs. This means that patients need to consult specialists to make sure how many times a specific medication should be taken at a day for all drugs including over-the-counter [13].

\section{Drugs' duration}

The duration of the drug to be taken is the "maximum quantity of medication that can be covered in a specified time period. This definition clarifies the necessity for duration of the medication to be written clearly on the prescription [13]. Even though the majority of the drugs in prescriptions (51.09\%) collected have the duration on as compared to $(48.91 \%)$ of the drugs that have not the duration on, it is very essential that doctors write the duration just like the dose, dosage or other essential matters.

\section{Meal consideration}

As shown in (Figure 2) The majority (64.10\%) of the drugs prescribed in Duhok city are found without any consideration to food intake, Only, $17.32 \%$ of the prescriptions are found with 'after/before meal' clearly written and in $18.58 \%$ with no need to write the 'after/ before meal' on the prescription because they are not administered orally. The presence of food within the GI tract impacts significantly on transit profiles, $\mathrm{pH}$, and drug solubilization capacity. Consequently, food would be expected to affect the absorption of co-administered drugs when their physicochemical properties are sensitive to these changes [14].

Interaction between foods and drugs can have profound influence on the success of drug treatment and on the side effect profiles of many drugs. The clinical significance of drug-food interactions can be variable. Drug-food interactions can lead to a loss of therapeutic efficacy or toxic effects of drug therapy. Generally, the effect of food on drugs results in a reduction in the drug's bioavailability; however, food can also alter drug clearance [15].

\section{Physicians' information}

Luckily,in Duhok city $100 \%$ of the prescriptions are found with the physicians' names, their specialty, and their address written. The only thing that only $61.63 \%$ of the prescriptions have it is the physician registration number, as the (Figure 3 ) shows.

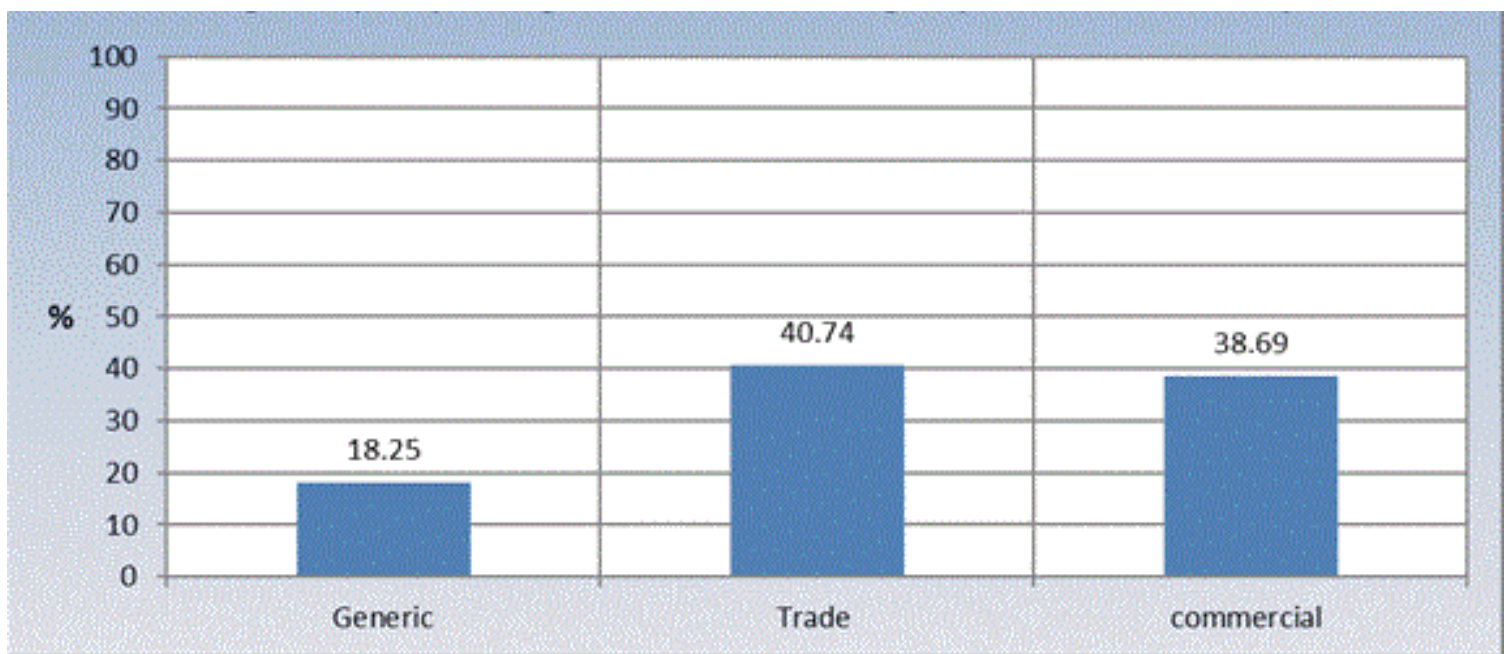

Figure 1: Drug's name writing style in duhok city. 


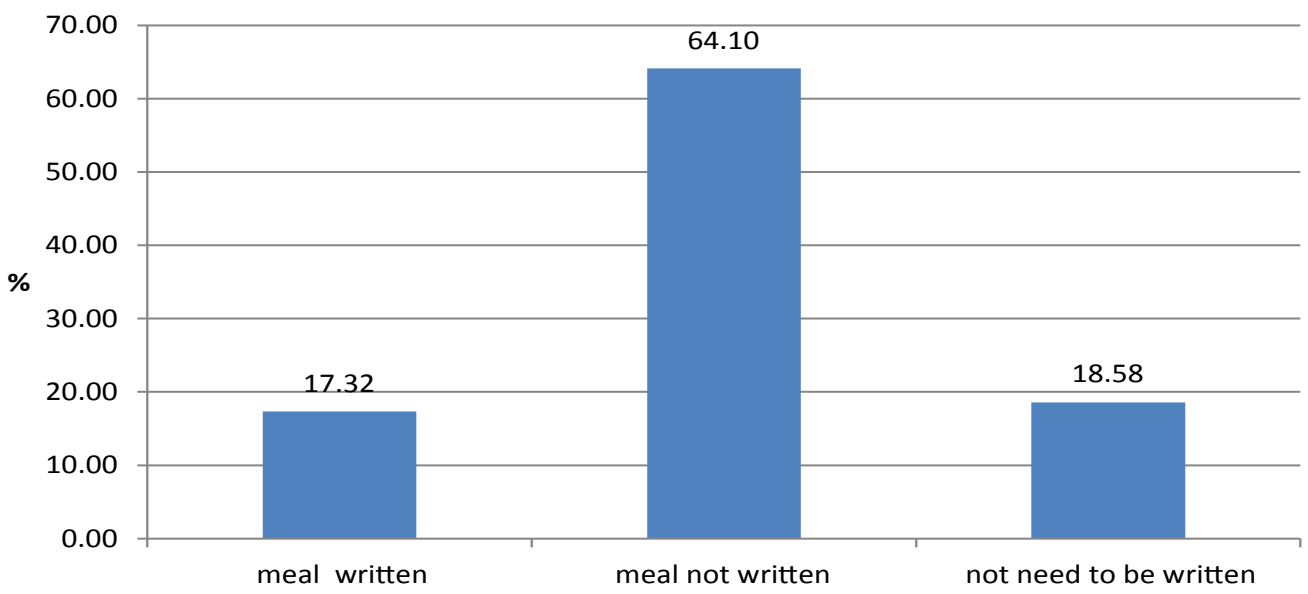

Figure 2: Meal consideration in prescriptions in duhok city.

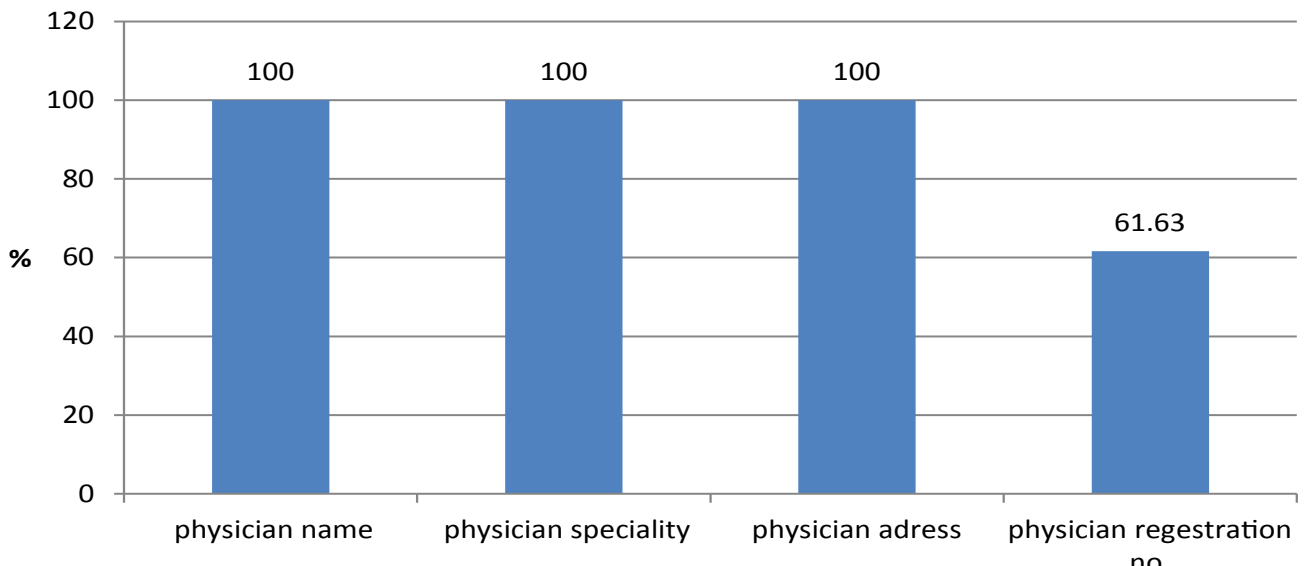

no.

Figure 3: Physician information in prescriptions in duhok city.

So far, all the factors that we discussed in this research on one hand and the physicians information on the prescription on the other are important to be considered. Meyer from a hospital and clinic in Texas mentioned that through a survey sent to 71 outside pharmacies requesting information on problems related to prescriptions indicated that $96 \%$ of responders (one physician and one pharmacist) believed that failure to print the prescriber name was one of the main problems [16]. Blatt et al. have shown that $20-30 \%$ of prescriptions from a central hospital in Yaounde, Cameroon, did not include the name and the degree of the prescriber [17].

A registration number is a number assigned to a health care by the Kurdistan physician syndicates allowing them to practice medicine in Kurdistan region of Iraq. It is a unique identifier for anyone who can prescribe medications.

\section{Patients' information}

There is no doubt about the fact that some pieces of personal information of the patient on the prescription are highly important. The most important ones are: name of the patient and his/her age and sex. $96.32 \%$ of the prescriptions collected include the name of the patient, $46.90 \%$ includes the age, and only $5.43 \%$ includes the sex as clearly shown in (Figure 4), this disagrees with the study done in
Saudi Arabia in which 5.4\%, $22.7 \%$ and $48.7 \%$ of the prescription were deficient in patient's name, age, and sex, respectively. This might be attributed to that the receptionist, being in a hurry, writes only patient's name, rather his age and sex [18]. Francois et al. in a French university hospital reported that complete patient information was provided in only $35.5 \%$ of prescriptions [11].

\section{Prescriptions general information}

Moreover, general information on the prescription is as important as the personal information. Looking at the (Figure 5), it is clearly seen that $89.73 \%$ of the prescriptions include the date and $87.60 \%$ of them include the signature.

Unfortunately $48.06 \%$ of the collected prescriptions include pharmaceutical company advertisement. The complex financial entanglements between the pharmaceutical industry and the medical profession have called into question the objectivity and independence of physicians. The chief concerns have been raising pharmaceutical costs and drug safety. These concerns have increased as some heavily marketed drugs have been revealed to pose public health risks. The interaction between physicians and the pharmaceutical industry can be viewed in terms of supply and demand. The pharmaceutical industry has the money, which it can supply to physicians in various forms such 


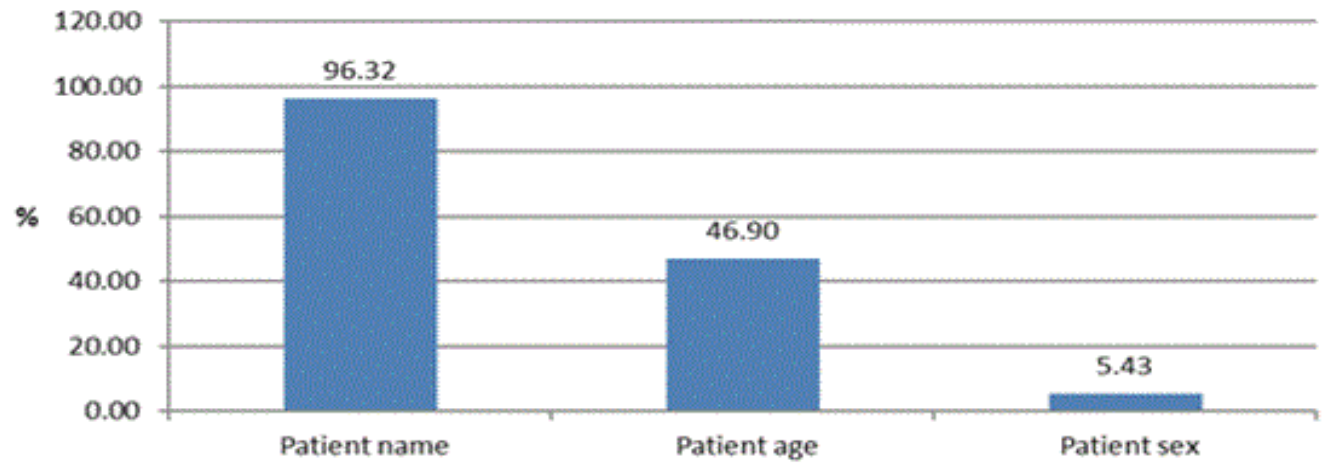

Figure 4: Patients information in prescriptions in duhok city.

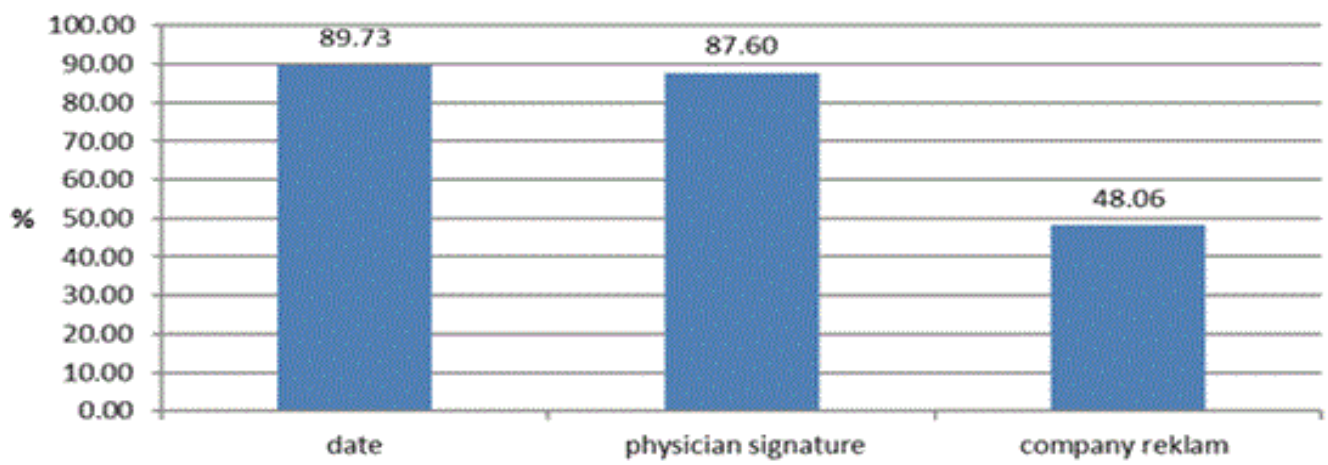

Figure 5: General information in prescriptions in duhok city.

as promotional gifts, entertainment, free drug samples, and funding for continuing medical education. Problems can and often do arise because the relationship between physician and pharmaceutical company is open to varying degrees of abuse [19].

Although some positive outcomes were identified (improved ability to identify the treatment for complicated illnesses), most studies found negative outcomes associated with the interaction. These included an impact on knowledge (inability to identify wrong claims about medication), attitude (positive attitude toward pharmaceutical representatives; awareness, preference, and rapid prescription of a new drug), and behavior (making formulary requests for medications that rarely held important advantages over existing ones; no rational prescribing behavior; increasing prescription rate; prescribing fewer generic but more expensive, newer medications at no demonstrated advantage) [20].

\section{Conclusion}

Results of this study showed that many errors found in prescriptions reviewed and most of the physicians don't follow the rules for standard prescribing pattern. Moreover, patients might be at risk of therapeutic failure due to errors happen during the prescription writing, dispensing and administration. Finally, many prescriptions contain reclame for pharmaceutical companies which are prohibited according to Iraqi's law and ethically unaccepted.

\section{Recommendations}

1. For drug name: Use of a generic formulation instead of a brand or commercial names for multisource drugs (that is, those with $\geq 1$ generic available) could be one mechanism for limiting drug expenditures. Patients and pharmacists may also influence whether a generic is dispensed for a multisource product. Practically, what doctors need to do in this case is to write the generic name of the medicine on the prescription.

2. Dose written in the prescription is most important especially in the pediatric and elderly who have different pharmacokinetic and pharmacodynamics profile compare to adult the dose also will be different so need to be written.

3. For poor handwriting: Technological solutions are almost without limit. Among them are dictation systems for all prescriptions, letters, notes, and orders; computer order entry; and typed, preprinted prescription pads and order pages for computer generated prescriptions.

4. Writing the dosage form of the prescribed drug is important because each drug may be available in more than one dosage forms each has differ onset and duration of action than the others.

5. The strength of the drug indicates that how many milligrams each tablet, suppository, or milliliter of fluid should contain must be mentioned. Internationally accepted abbreviations should be used: $\mathrm{g}$ for gram, $\mathrm{ml}$ for milliliter. In prescriptions for controlled drugs or those with a potential for abuse it is safer to write the strength and total amount in words, to prevent tampering. Instructions for use must be clear and the maximum daily dose mentioned. Use indelible ink.

6. Frequency of medication is important in order to avoid over or under the use, is also one single important psycholinguistic variable 
Citation: Abdulkareem RA, Omer QBA, Haji SD, Zozankh E, Rasheed NM, et al. (2016) Errors and Omissions in Private Clinics Prescriptions: A Survey of Prescription Writing In Duhok, Kurdistan Region- Iraq. J Pharmacovigilance 4: 215. doi:10.4172/2329-6887.1000215

affecting error on word memory and prescription.

7. Administration of drug, some drug have long or short duration to be use in order to give benefit to the patient, duration written help to avoid toxicity of drug.

8. Physicians and Pharmacists in every practice setting need to be vigilant in monitoring for potential drug-food interactions and advising patients regarding foods or beverages to avoid when taking certain medications. It is imperative for pharmacists to keep up-to date on potential drug-food interactions of medications, especially today's new drugs, so that they may counsel properly to the patients.

9. It is of paramount importance that physicians avoid putting their personal interests, or the interests of a pharmaceutical companies, before the interests of their patients by, for example, prescribing a particular drug to a patient and receiving some benefit-financial or otherwise-from the pharmaceutical company that manufactures it. It is unacceptable to receive material or financial gain for prescribing a specific drug.

10. Registration number is needed in the prescription for further authentication of the physician.

11. Date of prescribing should be written in order to know the validity of the prescription and to avoid unnecessary refilling of prescription.

12. Patient's name in the prescription should be written for proper identification of a patient. A prescription is meant for an individual, and there may be two clients at the pharmacy with the same first/last name whose prescription may get exchange.

13. Patient's age and weight is useful especially for children whom dosage is based on body weight its acts as the safety measure against dosage error.

14. Patient sex is important because some time some name associated with both male and female, and the pharmacy staff may not be able to assess whether the name is that of male or female.

\section{References}

1. Kumari R, Idris M, Bhushan V, Khanna A, Agrawal M, et al. (2008) Assessment of prescription pattern at the public health facilities of Lucknow district. Indian J Pharmacol 40: 243-247.

2. Mazzullo JM, Lasagna L, Griner PF (1974) Variations in interpretation of prescription instructions: the need for improved prescribing habits. JAMA 227 929-931.
3. Meyer TA (2000) Improving the quality of the order-writing process for inpatient orders and outpatient prescriptions. Am J Health Syst Pharm 57: S18-S22.

4. DeCara JM, Croze S, Falk RH (1998) Generic warfarin: a cost-effective alternative to brand-name drug or a clinical wild card?. chest 113: 261-263.

5. Brennan TA, Lee TH (2004) Allergic to generics. Ann Intern Med 141: 126-130.

6. Fok M, Lo A (2002) Quantifying the Impact of Prescription-Related Problems on Pharmacy Workload, The Can J Hosp Pharm 55: 313-319.

7. Ni KM, Siang CS, Ramli MNB (2002) Noncompliance with prescription writing requirements and prescribing errors in an outpatient department, Malaysian Journal of Pharmacy 1: 45-50.

8. Charman WN, Porter CJ, Mithani S, Dressman JB (1997) Physicochemical and physiological mechanisms for the effects of food on drug absorption: the role of lipids and pH. J Pharm Sci 86: 269-282.

9. Ismail MYM (2009) Drug food interactions and role of pharmacist. Asian Journa of Pharmaceutical and Clinical Research 2: 1-10.

10. Boehringer PA, Rylander J, Dizon DT, Peterson MW (2007) Improving the Quality of the Order $\square$ Writing Process for Inpatient Orders in a Teaching Hospital. Qual Manag Health Care 16: 215-218.

11. Francois P, Chirpaz E, Bontemps H, Labarere J, Bosson J, et al. (1996) Evaluation of prescription-writing quality in a French university hospital. Clin Perform Qual Health Care 5: 111-115.

12. Soldin OP, Chung SH, and Mattison DR (2011) Sex differences in drug disposition. J Biomed Biotechnol 2011.

13. Brodell RT, Helms SE, KrishnaRao I, Bredle DL (1996) Prescription errors Legibility and drug name confusion. Arch Fam Med 6: 296-298.

14. Peterson AM, Nau DP, Cramer JA, Benner J, Gwadry $\square$ Sridhar F, et al (2007) A checklist for medication compliance and persistence studies using retrospective databases. Value Health 10: 3-12.

15. Kapp RW (2016) Reproductive study evolution and IND submissions for the Food and Drug Administration. Reproductive Toxicology 109.

16. Sorensen AT (2000) Equilibrium price dispersion in retail markets for prescription drugs, Journal of Political Economy 108: 833-850.

17. Blatt A, Chambon R, Lemardeley $P$ (1997) Legal format and costs of prescriptions at the Central Hospital in Yaounde, Cameroon. Med Trop (Mars) 57: $37-40$.

18. Irshaid Y, Al Homrany M, Hamdi A, Adjepon Yamoah K, Mahfouz A (2005) Compliance with good practice in prescription writing at outpatient clinics in Saudi Arabia. East Mediterr Health J 11: 922-928.

19. Komesaroff PA, Kerridge $\mathrm{IH}$ (2002) Ethical issues concerning the relationships between medical practitioners and the pharmaceutical industry. Med J Aust 176: 118-122.

20. Wazana A (2000) Physicians and the pharmaceutical industry: is a gift ever just a gift?. JAMA 283: 373-380. 